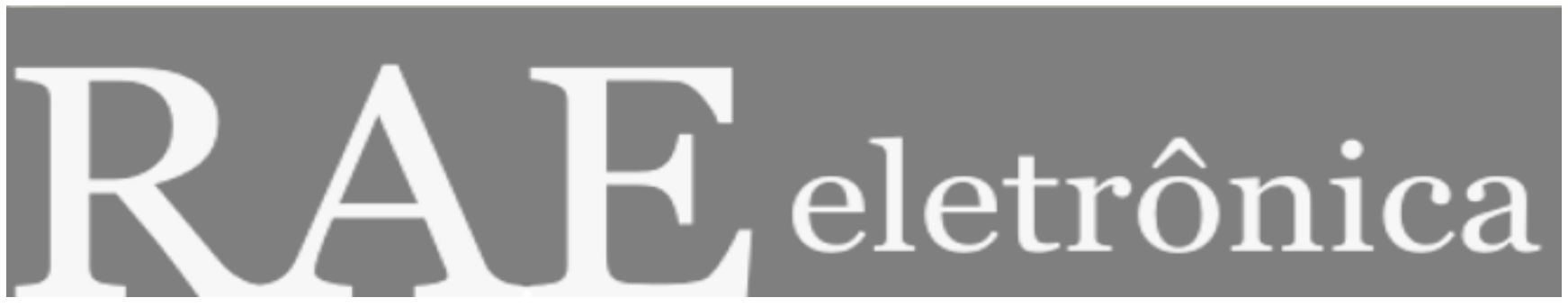

NAVEGABILIDADE E INCLUSÃO DIGITAL: USABILIDADE E COMPETÊNCIA

Por:

Alexandre Magno Dias Silvino

Júlia Issy Abrahão

RAE-eletrônica, v. 2, n. 2, jul-dez/2003.

http://www.rae.com.br/eletronica/index.cfm?FuseAction=Artigo\&ID=1808\&Secao=CIENCIA\&Volu $\mathrm{me}=2 \&$ Numero $=2 \&$ Ano $=2003$

CCopyright, 2002, RAE-eletrônica. Todos os direitos, inclusive de tradução, são reservados. É permitido citar parte de artigos sem autorização prévia desde que seja identificada a fonte. A reprodução total de artigos é proibida. Os artigos só devem ser usados para uso pessoal e nãocomercial. Em caso de dúvidas, consulte a redação: redacao@rae.com.br.

A RAE-eletrônica é a revista on-line da FGV-EAESP, totalmente aberta e criada com o objetivo de agilizar a veiculação de trabalhos inéditos. Lançada em janeiro de 2002, com perfil acadêmico, é dedicada a professores, pesquisadores e estudantes. Para mais informações consulte o site www.rae.com.br/eletronica.

RAE-eletrônica

ISSN 1676-5648

(C)2002 Editora: Fundação Getulio Vargas - Escola de Administração de Empresas de São Paulo.

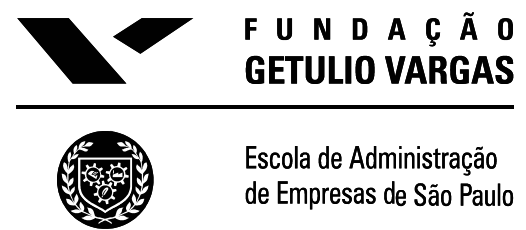




\title{
NAVEGABILIDADE E INCLUSÃO DIGITAL: USABILIDADE E COMPETÊNCIA
}

\author{
Alexandre Magno Dias Silvino \\ Doutorando em Psicologia. Mestre em Psicologia Organizacional e do Trabalho. \\ Endereço: Campus Universitário Darcy Ribeiro CEP 70.000-000 - Brasília, DF \\ Email: asilvino@terra.com.br \\ Interesse de Pesquisa: Ergonomia Cognitiva votada para as situações de trabalho informatizado, \\ ênfase em inclusão digital.
}

\section{Júlia Issy Abrahão}

Professora. Doutora Adjunto IV da Universidade de Brasília. Coordenadora do Laboratório de Ergonomia.

Endereço: Campus Universitário Darcy Ribeiro CEP 70.000-000 - Brasília, DF

Email: abrahao@unb.br

Interesse de Pesquisa: Ergonomia Cognitiva votada para as situações de trabalho informatizado.

\section{Resumo}

Este artigo, de cunho teórico, articula, apoiado no referencial da Ergonomia Cognitiva os critérios de usabilidade, e sua pertinência na avaliação de sistemas informatizados em rede, como uma das perspectivas possíveis para minimizar a exclusão digital. Nesse sentido, aponta novos elementos a serem agregados conceitualmente na construção ou avaliação de websites, tais como o conceito de competência para ação - apreendida pela via das estratégias operatórias e heurísticas adotadas pelos usuários e o processo decisório apoiado nas representações para ação. Ao final, são apresentadas considerações no sentido de articular estas variáveis com os critérios de navegabilidade e com os conceitos subjacentes aos princípios de inclusão digital.

Palavras-chave: Ergonomia Cognitiva, Inclusão Digital, Navegabilidade, Competência

\begin{abstract}
Based on the referential theory of the Cognitive Ergonomics, this theoretical article articulates the usability criteria, and its pertinence to the evaluation of the web informatization systems, as one of the possible perspectives to minimize the digital exclusion. This way, the article points out new elements that can be conceptually added in the construction or evaluation of websites, such as the concept of competency to action - understood through the operatory and heuristics strategies adopted by the users, and the decision process based on the representations for action. At the end, considerations are made for the articulation of these variables with navigation criteria, and with the concepts which are behind the principles of digital inclusion.
\end{abstract}

Key-words: Cognitive Ergonomics, Digital Inclusion, Navigation, Competence 


\section{Introdução}

A evolução tecnológica tem assumido no mundo, e em particular no Brasil, um papel estratégico no desenvolvimento econômico, social e cultural. Diversos recursos têm sido empregados pelo Governo Federal, empresas e indústrias no sentido de modernizar e otimizar os processos produtivos e, por conseqüência, seus produtos finais.

A telemática, área de conhecimento que congrega informática e telecomunicações, demonstrou sua força pela "capilaridade" que atingiu no setor terciário, transformando as estruturas das tarefas e a configuração dos postos de trabalho. Em diferentes tipos de serviços é comum encontrar todo o processo produtivo, ou parte dele, mediado por sistemas informatizados. Em geral, observa-se nestas situações um aumento na produtividade e maior controle nas diversas etapas de produção (macro e micro processos). Contudo, constata-se, também, um significativo aumento na quantidade de casos de doenças ocupacionais, pouca flexibilidade na organização do trabalho, apesar do discurso dominante da flexibilidade, e necessidade de aquisição de novas competências dada a complexificação das tarefas.

Da mesma forma, grandes empresas, bancos e órgãos governamentais estão canalizando esforços no sentido de aumentar a oferta de serviços virtuais. No entanto, os usuários destes serviços constituem uma população cujas características primam pela variabilidade do seu perfil. A inclusão digital buscada por essas organizações é confrontada a dificuldades de naturezas distintas como, por exemplo, o grau de instrução e a renda familiar.

As eleições ocorridas em 2002, no Brasil, apontam de forma clara que, nas cidades onde foi introduzida a impressora acoplada à urna eletrônica, a população de baixa renda teve um elevado tempo médio gasto no processo, conforme relatado na mídia, revelando as dificuldades desta camada da população na interação com o artefato. Se uma ação aparentemente simples como esta apresentou dificuldades, é factível supor que, na atual conjuntura, o acesso aos serviços oferecidos pelo Estado e pela rede bancária, por exemplo não favorecem a inclusão digital da forma como estão disponibilizados.

O objetivo deste ensaio é sugerir uma base conceitual que identifique as variáveis que, ao serem incorporadas na concepção ou avaliação de interfaces gráficas de internet, favoreçam a navegabilidade e, conseqüentemente, o acesso de pessoas com pouca experiência, baixa escolaridade e diferente faixa etária.

O artigo articula, apoiado no referencial teórico da Ergonomia Cognitiva, os critérios de usabilidade, e sua pertinência na avaliação de sistemas informatizados em rede, como uma das perspectivas possíveis para minimizar a exclusão digital. Nesse sentido, aponta novos elementos para serem agregados conceitualmente na construção ou avaliação de websites, tais como o conceito de competência para ação - apreendida pela via das estratégias operatórias e heurísticas adotadas pelos usuários e, o processo decisório apoiado nas representações para ação. Ao final, são apresentadas considerações no sentido de articular estas variáveis com os critérios de usabilidade e com os conceitos subjacentes aos princípios da inclusão digital.

\section{Inclusão Digital}

Uma das dimensões da inclusão digital pode ser apreciada pela disponibilização do acesso às informações e serviços prestados via internet à maioria de uma população. Neste sentido, trata-se de uma democratização da informática que pressupõe diferentes níveis de ação por parte do governo, de instituições de ensino, empresas privadas e terceiro setor. 
De fato, este é um problema relevante, uma vez que $90 \%$ da população brasileira não se beneficia deste tipo de tecnologia. De acordo com o COMITÊ PARA A DEMOCRATIZAÇÃO DA INFORMÁTICA - CDI (2002), o legado deixado pelo governo passado é o de implantação de infra-estrutura em internet em 6\% dos municípios brasileiros. Estes dados são referendados pelo relatório do PROGRAMA DAS NAÇÕES UNIDAS PARA O DESENVOLVIMENTO - PNUD (2002) que divulga o índice de avanço tecnológico comparado de 72 países. O Brasil, segundo este relatório, ocupa o $43^{\circ}$ lugar e, embora seja considerado uma potência tecnológica, a distribuição e o acesso à tecnologia da informação é muito desigual.

A oferta de serviços do Governo Federal e das organizações em geral pela via da internet encontra como desafios: (a) favorecer o acesso do cidadão ao mundo virtual, (b) reduzir o analfabetismo digital (que implica fornecer noções básicas sobre sistemas informatizados) e (c) melhorar a qualidade da interface gráfica disponibilizada, adaptando-a ao seu público-alvo.

Figura 1 - Desafios para a Inclusão Digital

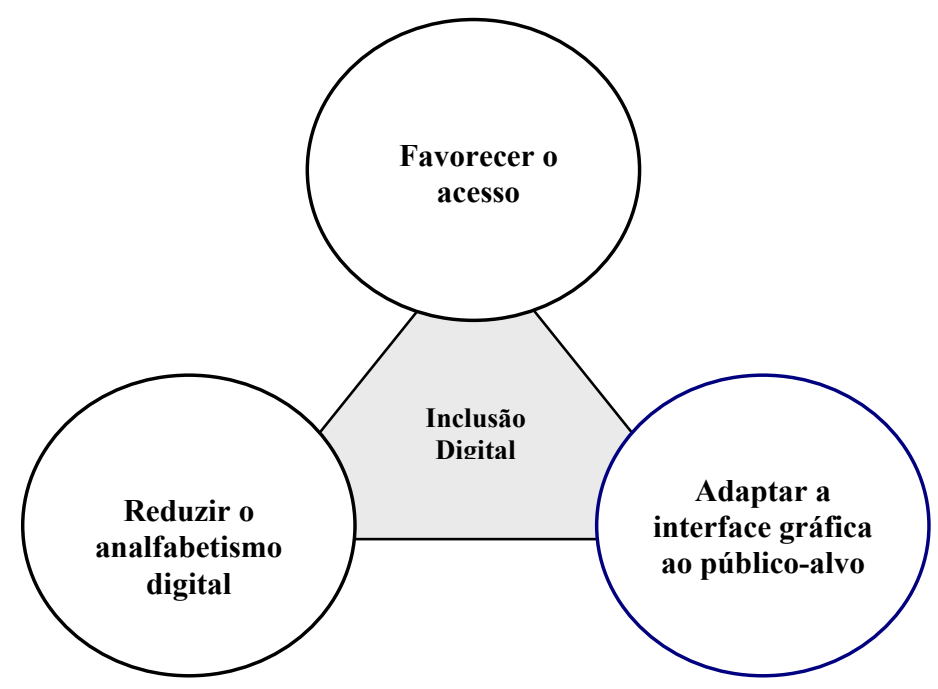

A REVISTA DA SOCIEDADE DIGITAL (2002) relata a criação de infocentros em São Paulo com 10 computadores disponíveis para qualquer pessoa, refletindo uma característica comum aos projetos de Inclusão Digital: criar locais comunitários para acesso popular. Iniciativas isoladas como esta despontam em alguns municípios brasileiros financiadas pelo Estado e o Terceiro Setor. No entanto, elas ainda estão longe de atender uma parcela significativa da população.

A questão que se coloca é como aumentar o acesso à sociedade da informação. Diferentes autarquias oferecem ao cidadão serviços virtuais que representam ganhos significativos em níveis distintos. Dois exemplos de sucesso são o Receita Net da Receita Federal, e a Concessão de Benefícios da Previdência Social. Organizações como estas atendem uma clientela heterogênea no que se refere à idade, grau de instrução, nível econômico e familiaridade com sistemas informatizados - SI. De fato, quais são as camadas da população capazes de operar tais aplicativos? Malgrada a divulgação da alta freqüência de uso destes serviços e da sua função social, o que se verifica é que os cidadãos com baixa escolaridade solicitam a terceiros a mediação para o acesso ao serviço. Assim, por exemplo, são as patroas que solicitam o auxilio maternidade de suas empregadas domésticas. O princípio subjacente ao processo de informatização que deveria, por esta via, minimizar a exclusão digital encontra seus limites.

O sistema informatizado em rede, em última instância, é um artefato que media a comunicação entre 
uma instituição (pública, privada, ou até mesmo um indivíduo) e um usuário interessado no serviço oferecido. Embora não presencial, esta comunicação pressupõe:

a. uma troca dinâmica de dados - ao entrar com um dado no sistema (ou optar por um ícone ou hipertexto) o usuário obtém uma resposta do sistema, bem como o alimenta com informações que podem validar o trabalho ou sugerir mudanças no sistema.

b. a utilização de signos comuns - ou seja, uma linguagem tanto de termos quanto de ícones que possam ser decodificadas pelos usuários.

c. a capacidade de antecipação de necessidades e procedimentos - para otimizar a comunicação e manter ativa (e vantajosa) a troca de informações para todos os envolvidos.

Considerando a variabilidade inter e intra individual da população, quais os critérios do ponto de vista conceitual deveriam ser integrados no projeto de concepção de sites com o intuito de minimizar a exclusão digital? Como facilitar a comunicação dos diferentes usuários com a interface disponibilizada?

Pode-se hipotetizar que é o número de pessoas que têm representações comuns sobre uma palavra ou conceito que determina a ação e que confere força a esta palavra ou conceito. Nesse sentido, pode-se avançar o pressuposto que a interface deve ser configurada de forma a não exigir, necessariamente, dos usuários um novo aprendizado para associar comandos e ações, tornando a navegação mais "intuitiva". Intuitiva no sentido de ser automática, ou processada inconscientemente, solicitando pouco esforço cognitivo - facilitando a ação e reduzindo a probabilidade de erros.

Outro critério importante é a navegabilidade que, além dos aspectos intrínsecos da usabilidade, engloba as características dos usuários, em particular as estratégias que adotam no processo de resolução de problemas e de tomada de decisão. Quando este critério não é incorporado na arquitetura de um site, mesmos os usuários mais experientes deixam de acessá-lo, quiçá aqueles semi-alfabetizados. Ao ser confrontado com uma lógica de representação muito distinta de seu modo de funcionamento, as dificuldades para se atingir um determinado objetivo assumem proporções enormes, sobretudo com pessoas cuja familiaridade tecnológica é ainda incipiente.

O desafio de popularizar a internet como uma grande difusora de informações e de prestação de serviços passa por uma interface gráfica que permita uma boa navegabilidade, conforme definida neste artigo. Este desafio é ainda maior uma vez que $95 \%$ da população brasileira ainda não teve acesso à internet (REVISTA DA SOCIEDADE DIGITAL, 2002).

Esta realidade, tal com está posta no Brasil, evidencia a necessidade de elaborar novos modelos metodológicos, instrumentos e técnicas, para se apreender as mudanças decorrentes do desenvolvimento tecnológico (MARMARAS e PAVARD, 2000; MARMARAS e KONTOGIANNIS, 2001; LEPLAT, 1986). A sugestão dos autores mostra sua pertinência, face ao fato de que as disciplinas que estudam o trabalho se confrontam com um objeto que demanda aferições indiretas e cujas medidas se inscrevem em um quadro de grande variabilidade: a cognição humana.

A intenção de popularizar a internet se insere em um contexto que sugere, também, a necessidade de uma nova abordagem com relação à amostra, sobretudo nas questões relativas à sua estratificação e quantidade. A complexidade da navegabilidade se configura cada vez que o usuário navega, pois ao ser confrontado às novas informações ele modifica suas representações e reconstrói as diferentes situações- 
problema que encontra. Considerando a diversidade de sites e, em cada um, as diferentes possibilidades de obter o resultado esperado, este processo sofre grande influência da linguagem utilizada. O papel dos termos de navegação, hiperlinks e ícones assume maior magnitude quando se busca atingir um grande número de usuários com experiência em internet, idade e grau de instrução diversificados.

A navegabilidade tal como delineada acima pressupõe o usuário como elemento central na criação do site, resgatando traços das suas representações, suas formas de enfrentamento dos problemas originados pelo contato com a interface gráfica e, principalmente, como este desenvolve estratégias a partir das competências que já possui. A relação entre estes diferentes processos cognitivos é entendida a partir do referencial da Ergonomia Cognitiva.

\section{Ergonomia Cognitiva}

A Ergonomia Cognitiva freqüentemente é associada à demanda de novos conhecimentos e instrumentos que permitam explicar as ações dos indivíduos e os mecanismos subjacentes a elas. Se por um lado o termo Ergonomia Cognitiva - EC é recente, por outro a área em questão não é propriamente nova. Considerando a capilaridade da informática em numerosos contextos, a EC tem sido associada somente aos estudos que tratam da inter-relação homem-computador, de tal sorte que CAÑAS E WAERNS (2001) apontam a abordagem de Interação Homem-Computador - IHC como sinônimo de EC. Tal posição é equivocada. Seu uso não está necessariamente ligado àquelas situações cuja atividade é informatizada, ou seja, esta disciplina extrapola a intenção de explicar a inter-relação homem-artefato somente na situação particular de sistemas informatizados.

É importante salientar que a Ergonomia Cognitiva não tem por objetivo elaborar uma "teoria do comportamento humano". Trata-se, antes, de analisar como uma teoria, ao ser operacionalizada, pode se mostrar pertinente ou não nas escolhas para delinear ferramentas de suporte cognitivo em situação de trabalho (GREEN e HOC, 1991). Assim, pode-se afirmar, parafraseando HOLLNAGEL (1997), que o objetivo da EC não é tentar entender a natureza da cognição humana, mas descrever como a cognição humana afeta o processo laborativo e por ele é afetada. Para tanto, ela busca otimizar as características do dispositivo técnico, adotando como base ou referência os processos cognitivos de uma determinada população.

A Ergonomia Cognitiva não é compreendida neste artigo na perspectiva de dependência com relação às abordagens da IHC. Enquanto esta busca descrever novos métodos de interação homens-artefatos, a Ergonomia Cognitiva tem como objetivo explicitar como se articulam os processos cognitivos face às situações de resolução de problemas nos seus diferentes níveis de complexidade. Nesse sentido, entende-se a IHC como um campo da Ergonomia Cognitiva.

A Ergonomia de natureza mais experimental decompõe os "objetos complexos em objetos simples", quando voltada para a aplicação, ela deve ser capaz de recompor estes objetos a fím de estabelecer modelos das atividades cognitivas. Assim, HOC E LIÉNARD (1990), propõem um enriquecimento dialético destas duas abordagens como forma de auxiliar a compreensão da cognição em situação.

A idéia geral é que a EC se apropria de determinados conceitos de uma maneira muito particular, buscando articular um referencial teórico compatível com as imposições das características dos estudos de campo. Nesse sentido, duas considerações são fundamentais para o olhar ergonômico sobre a cognição. O primeiro é como apreender e explicar o tratamento de informações num dado contexto mediado pelos objetivos e exigências da tarefa, associado às características das pessoas envolvidas. Logo, trata-se de uma cognição situada. O segundo é que este processo cognitivo implica na 


\section{ADMINISTRAÇÃO DE CIÊNCIA E TECNOLOGIA - NAVEGABILIDADE E INCLUSÃO DIGITAL: \\ USABILIDADE E COMPETÊNCIA \\ Alexandre Magno Dias Silvino - Júlia Issy Abrahão}

particularização de um conhecimento mais geral, para responder a uma situação posta com um fim específico, portanto, com caráter finalístico. Isto implica conceber um conceito de cognição em ação, ou seja, destinada a um fim específico que propicie uma intervenção no meio e que gere subsídios para os projetos de novos artefatos.

Sob esta perspectiva é que se incorpora o usuário, não somente nas suas características demográficas (como sexo e idade), mas, principalmente, na interação com a interface gráfica. Ao se adotar a atividade como fio condutor da análise, é possível recuperar as estratégias utilizadas para navegar, compreender como determinada população estrutura os problemas e como é construída a sua ação. Estas são características que compõem a competência do usuário em agir. Esta competência é posta em prática em um ambiente cuja inteligibilidade pode favorecer, ou não, a obtenção dos resultados esperados. Neste sentido, a navegabilidade é compreendida em função da usabilidade que o site apresenta, bem como pelas representações do usuário, suas estratégias de resolução de problemas e de como o processo decisório é constituído.

\section{Usabilidade e sistemas em rede}

O avanço da telemática e sua apropriação como instrumento de trabalho aponta para a necessidade de estudos que favoreçam a utilização deste artefato por diferentes camadas da população. Apesar da multiplicidade de variáveis que influenciam neste processo de interação entre o operador, o software e a tarefa, duas dimensões se mostram pertinentes aos objetivos deste trabalho: uma intrínseca, relativa à coerência interna do software, e uma extrínseca, onde a ênfase é colocada na interação do sujeito com o computador.

Em comum, essas dimensões incorporam uma série de princípios cujos objetivos estão voltados para a inteligibilidade e a facilidade de ação do operador, ou seja, buscam otimizar a navegabilidade. Tais princípios foram agrupados na forma de critérios ergonômicos por autores como SCAPIN (1990) e BASTIEN (1991 e 2003) e, têm sido estudados em diferentes contextos que sugerem outra forma de agrupamento, assim como interpretações como as propostas por CYBIS (2002).

\begin{tabular}{|c|c|}
\hline Critérios & Sub-critérios \\
\hline Condução & $\begin{array}{l}\text { - Presteza nas informações fornecidas } \\
\text { - Agrupamento e distinção de itens } \\
\text { - Feedback imediato } \\
\text { - Clareza nas características lexicais }\end{array}$ \\
\hline Carga de Trabalho & $\begin{array}{l}\text { - Brevidade } \\
\text { - Carga mental }\end{array}$ \\
\hline Controle Explícito & $\begin{array}{l}\text { - Ações explícitas } \\
\text { - Controle do usuário }\end{array}$ \\
\hline Adaptabilidade & $\begin{array}{l}\text { - Flexibilidade nos meios disponíveis } \\
\text { - Experiência do usuário }\end{array}$ \\
\hline Gestão de Erros & $\begin{array}{l}\text { - Proteção contra erros } \\
\text { - Qualidade da mensagem } \\
\text { - Correção de erros facilitada }\end{array}$ \\
\hline \multicolumn{2}{|l|}{ Homogeneidade/Consistência } \\
\hline \multicolumn{2}{|l|}{ Significância dos Códigos } \\
\hline Compatibilidade & \\
\hline
\end{tabular}

Fonte: Tabela elaborada segundo BASTIEN (1991 e 2003). 
Os critérios apresentados na tabela 1, quando incorporados conceitualmente no processo de concepção ou de avaliação de um site, apoiados em dados oriundos das características da população usuária, permitem identificar, nas diferentes telas de acesso os símbolos, as lógicas de funcionamento e os elementos que lhe são familiares, possibilitando uma nova formulação e/ou correção. Esta construção será, então, apoiada na lógica dos usuários e não somente na do "web designer" ou dos programadores.

Em uma pesquisa realizada com estudantes universitários e secundaristas, SARMET e SILVINO (2002, p. 040) sugerem critérios complementares para avaliar a navegabilidade de sites. Segundo o estudo, três critérios se mostram pertinentes para os usuários no processo de avaliação da navegabilidade :

- Aspectos do sistema - refere-se à qualidade ou capacidade dos equipamentos que o usuário possui para acesso à Internet. O site deve permitir que diferentes recursos facilitem a apreensão do seu conteúdo pelo usuário, sem desconsiderar que as tecnologias utilizadas não podem estar incompatíveis com as mais comuns encontradas na rede.

- Arquitetura do conteúdo - diz respeito à forma como o conteúdo do site é disposto, tornado sua apreensão facilitada no que tange à utilização de recursos cognitivos (como a informação é redigida ou a utilização de ilustrações) e como ela é disponibilizada (em diversos níveis, em uma só estrutura).

- Estética funcional - trata-se das questões relativas à proporção, equilíbrio, harmonia em função dos traços, estilo de redação, cores que podem facilitar ou dificultar a navegabilidade do usuário.

Esses critérios apresentam um diferencial não apenas como norteadores da construção, o que obviamente lhes conferem atributos que podem facilitar ou dificultar a navegação, mas, principalmente, por constituírem variáveis factíveis de serem aferidas na avaliação de sites.

De forma geral, os critérios apresentados podem ser considerados como indicadores de base para que o site possa ser utilizado com menor dificuldade pelos usuários. Embora, esta seja uma problemática bem discutida na literatura, a maioria dos sites ainda não incorpora os critérios apontados. Por outro lado, a procura por checklists elaborados com base nestes critérios tem crescido. Este movimento denota a preocupação em integrar o usuário, mas por outro lado, evidencia a busca por um método rápido e pouco dispendioso para a organização. Trata-se de uma ilusão, uma vez que a população alvo apresenta características que determinam a opção de uma configuração em detrimento de outra. Dito de outra forma, os critérios per se são impessoais no sentido de apontar, por exemplo, a necessidade de ícones, mas não sugerem os ícones mais apropriados.

Não é o caso de negar a relevância dos critérios, pelo contrário, busca-se pontuá-los como "instrumento" fundamental, reconhecendo seus limites e salientando a necessidade de incorporar o usuário em outro nível. Esse usuário que possui experiências na lida com tecnologias, internet, serviços públicos e como consumidor, detém conhecimentos diversos, os quais compõem a base para sua ação inclusive no mundo virtual. A proposta é não negligenciar este conhecimento, esta representação sobre o mundo, incorporando-os à interface no sentido de aproximar ao máximo do mundo ao qual ele está familiarizado.

Como apreender este conhecimento? Como é construída a competência do usuário? 


\section{A competência para Ação}

Em ergonomia, a noção de competência articula as dimensões do conhecimento necessário para ação e da habilidade em agir. As competências são consideradas em função da atividade, referindo-se sempre à competência em executar uma dada tarefa. De acordo com MONTMOLLIN (1995, p. 25) é preciso considerar o aspecto cotidiano da competência, segundo ele o "(...) operador não é apenas ativo $-e$ ativo eficazmente - aqui e agora, ele o foi lá e ontem, e pode-se prever que ele o será em outro lugar, $e$ amanhã (...)".

Esses pressupostos reportam a um conhecimento que é antecedente e que pode sofrer transformações e, portanto, evoluir. Duas categorias de conhecimentos são apresentados por MONTMOLLIN (1995): os chamados conhecimentos declarativos, cujo conteúdo permite uma descrição da ação baseada fundamentalmente nos objetivos a serem alcançados e os ditos procedimentais, cujo conteúdo está associado ao uso do sistema - a um conjunto de regras operacionais (STERNBERG 2000; ANDERSON, 2000; BEST 1995). Esse processo evolutivo é, antes de tudo, adaptativo, uma vez que as competências podem se tornar obsoletas, tanto pelo envelhecimento do sujeito quanto pelo desenvolvimento tecnológico.

Ainda segundo MONTMOLLIN (1995), o conceito de competência para Ergonomia remete à noção de expertise. Para a EC o resultado do cotejamento entre as estratégias operatórias adotadas na resolução de problemas e na gestão dos recursos (tanto cognitivos quanto materiais) é que os trabalhadores diferenciam suas competências.

HANISH, KRAMER e HULIN (1991) demonstraram como os modelos mentais de alguns usuários experts facilitam a sua inserção em um sistema complexo. Para tanto, basearam seus estudos em três componentes do modelo mental dos usuários: (a) os conhecimentos declarativos e procedimentais, (b) a percepção que eles possuem sobre o sistema e (c) a similaridade de uso entre as características do sistema adotado.

ADELSON (1984) e KOUBECK e SALVENDY (1991) apontam uma diferença marcante entre as representações dos experts e as dos novatos. Enquanto os primeiros trabalham mais em um nível abstrato, baseados em conhecimentos declarativos, os segundos possuem representações menos abstratas, associadas em maior grau aos conhecimentos procedimentais, ou seja, em como o programa opera. ADELSON (1984) procura demonstrar que, em tarefas que exigem do sujeito um procedimento passo a passo, estas características atribuídas aos novatos podem auxiliá-los a superar operadores mais experientes.

Alguns estudos relacionados ao grau de expertise do operador estão associados à questão da otimização da interface. Segundo KOUBEK e SALVENDY (1991) compreender as diferenças existentes entre operadores experts e novatos permite compreender o processo de aquisição de habilidades cognitivas, bem como identificar os elementos necessários para alcançar uma predeterminada performance.

A competência está intimamente relacionada à chamada gestão dos recursos. Quanto mais experiente e competente for o sujeito, melhor ele tende a gerir bem seu tempo, materiais, conhecimentos, habilidades e equipamentos. AMALBERTI (citado por MONTMOLLIN, 1995) sugere que, por vezes, a diferença entre experts e novatos encontra-se nesta gestão de recursos e não no volume de conhecimentos. A atividade é construída a partir desta gestão: para tanto, um mecanismo de base é posto em ação consistindo em automatizar seu savoir-faire através da aprendizagem, o que provavelmente reduz a carga de trabalho para o indivíduo. Da mesma forma, são elaborados raciocínios 
heurísticos que atuam como um "compromisso cognitivo" regulando atividades como as de planificação, antecipação e controle do risco (AMALBERTI, citado por MONTMOLLIN 1995).

É importante salientar que para colocar em ação os conhecimentos e habilidades que possui, o sujeito dispõe de uma 'estrutura ou ferramenta' cognitiva que funciona como um esquema ou um mapa da situação - englobando os fatores com os quais está mais familiarizado ou que são significativos no contexto. Esta estrutura pode ser chamada de representação, mapa mental, imagem mental, modelo mental de acordo com a sua especificidade, ou seja, dizem respeito às formas de armazenamento e estruturação diferenciados do conhecimento. Esses conceitos são apresentados na literatura com graus diferenciados de similaridade. No entanto, eles têm em comum a função de servirem com suporte para a ação.

\section{As representações para ação}

Interessa, para a EC, a noção de representações que, de acordo com GRIZE (citado por MONTMOLLIN, 1995), podem ser entendidas tanto em um sentido técnico, quando estas se referem à expressão de um conhecimento com a ajuda de signos, quanto em um sentido psicológico, quando faz referência a um conjunto de valores e propriedades atribuídas a um fenômeno para armazenamento na memória.

TEIXEIRA (1993) define as representações como estados mentais que promovem um elo entre o organismo e um determinado contexto. Desta forma, têm como característica o fato de trazer em si mesmas os objetos aos quais se referem, independentemente de os mesmos estarem ou não em sua presença.

Em comum, tais conceitos apresentam uma característica de apreensão de elementos de um contexto, que permite identificá-lo e compreendê-lo. Embora de forma não explícita, articulam uma noção de um funcionamento cognitivo que é voltado para a execução de uma atividade - desenvolvendo a idéia de uma representação voltada à ação.

Como um dos precursores desta idéia, OCHANINE (1992) trabalha com a noção de 'imagem operatória', ou seja, que os indivíduos criam um esquema onde são recortadas as informações mais importantes à execução de uma atividade e as organizam buscando colocar em evidência as relações existentes entre elas. Uma imagem das operações é esquematizada pela relação entre as variáveis conformadoras do fenômeno e reforçada pela experiência do sujeito.

Neste caso, embora sirvam à ação, as representações não são mapas de procedimentos completos. Ao contrário, como alerta AMALBERTI (1991), os modelos mentais adotados em situação de tomada de decisão tendem a ser "incompletos, muito pessoais, instáveis e não científicos". Esse autor observa que tais características se aproximam das propriedades da 'imagem operatória' proposta por OCHANINE. Um conjunto de características das representações para ação são definidas por TEIGER (1993, p.319 ). Segundo os autores as representações:

- Atuam como processos mentais ativos de tomada de consciência e apropriação das situações;

- Seu aspecto essencial reside nos conteúdos e significados construídos em função do contexto e da atividade executada;

- Para abordagem ergonômica a questão central relativa às 'representações para ação' consiste em 


\section{ADMINISTRAÇÃO DE CIÊNCIA E TECNOLOGIA - NAVEGABILIDADE E INCLUSÃO DIGITAL: \\ USABILIDADE E COMPETÊNCIA \\ Alexandre Magno Dias Silvino - Júlia Issy Abrahão}

compreender como os sujeitos constroem os problemas encontrados e como elaboram soluções apropriadas;

- As 'representações para ação' possuem como função primeira construir significados de uma situação que permitam ao sujeito agir sobre ela, desta forma seu caráter finalístico atua como "organizador de suas atividades cognitivas";

- O agir permite a (re)estruturação das representações, fornecendo novos elementos e situações que enriquecem o conteúdo que o indivíduo formou anteriormente;

- O desenvolvimento das 'representações' é um processo qualitativo onde a aprendizagem ocorre por meio de uma reorganização dos conteúdos e do funcionamento cognitivo, e não através de um acúmulo quantitativo de conhecimentos;

- Este desenvolvimento é contínuo onde, mesmo que parte do conteúdo venha a se constituir parte integrante da memória permanente, o processo representativo não se cristaliza e continua a se modificar no contato com a atividade.

Tais características evidenciam a relação existente entre ‘ação' e 'representação', no que tange à gênese e evolução das representações via o agir no ambiente, mas, sobretudo, o papel das representações como norteadora das tomadas de decisão do indivíduo (TEIGER, 1993). As representações, em última análise, são traços de memória que são evocadas mais (ou menos) facilmente diante de determinados estímulos. Ao se considerar os traços de memória em uma rede semântica, a evocação se dá pela ativação e inibição de diferentes traços que podem estar diretamente envolvidos, bem como traços não diretamente envolvidos, que influenciam a interpretação da situação. Assim, pode-se afirmar que quanto maior o número de elementos familiares na página, maior a probabilidade de evocação de traços, ou reconstrução de representações, que permitam ao sujeito agir minimizando os erros e a possibilidade de fracasso.

Os ícones e termos adotados, então, influenciam diretamente nas representações dos usuários. Os menos experientes, ou os excluídos digitais, possuem poucas possibilidades de ativação de uma rede que favoreça uma ação efetiva. Se os elementos da interface gráfica forem elaborados a partir da representação que as pessoas têm do mundo real e, principalmente, a partir dos indicadores da atividade, ao ser submetido a estes estímulos os usuários podem recuperar informações mais adaptadas ao contexto. De fato, isto é relevante na medida em que a oferta de serviços via internet pode seguir a lógica deste serviço muitas vezes já familiar em outro contexto.

Um exemplo ilustra como operacionalizar os pressupostos citados acima. Ao acessar o site de um banco a fim de pagar a conta de água o usuário pode entrar na página correta, que contém os campos disponibilizados para esta operação, a partir de diferentes caminhos. Termos (palavras) ou ícones relativos ao conhecimento que o usuário tem sobre o pagamento presencial de contas compõem a sua representação para ação, ou modelo mental, que ele possui. Assim, ao navegar para pagar sua fatura, o ícone de uma torneira e/ou o termo "pagamentos" podem ser mais representativos e, portanto, mais acessíveis, do que termos como "convênios" ou "títulos", o que facilita ao sujeito tomar a decisão correta, ou de menor custo cognitivo, e atingir seu objetivo.

Esta relação depende da familiaridade (expertise) do usuário, o que ressalta a importância de investigar as representações do público-alvo do site. Esta variável assume uma dimensão maior quando este público não tem nenhuma familiaridade com ambiente virtual e baixa escolaridade. 
Considerando que a ação do indivíduo - ou seja, sua atividade - é guiada pela sua representação, é factível supor que uma mudança na ordem do comportamento é precedida por uma transformação das estruturas cognitivas. Vale a pena resgatar que a todo o momento é buscado um equilíbrio entre a dimensão do prescrito e a do real exigindo do sujeito uma redefinição constante do que deve ser executado, face à variabilidade inerente às ações possíveis (ABRAHÃO e PINHO, 1999). Assumindo como um sistema funcional que permite ao indivíduo agir de forma eficaz, as representações para ação auxiliam a gestão desse compromisso entre a tarefa e a atividade (WEILL-FASSINA, 1990).

Neste artigo, a competência é compreendida em uma matriz que articula, além dos conhecimentos e das representações para ação, as estratégias operatórias do usuário, para proceder a uma regulação entre o que lhe é exigido e a variabilidade das condições disponibilizadas.

\section{As estratégias operatórias}

A estratégia operatória é, por definição, intimamente relacionada à competência dos operadores e ao aspecto extrínseco da navegabilidade do site. Entende-se por estratégia operatória o processo de categorização, resolução de problemas e tomada de decisão que resulta em um modo operatório (seqüência de ações e operações) adotado pelo sujeito na interação com o artefato.

Os modos operatórios são, segundo GUÉRIN et al. (2001), resultado de uma regulação entre (a) os objetivos, (b) os meios disponibilizados, (c) os resultados produzidos e (d) o estado interno do operador. A relação entre estratégia e modo operatório fica evidenciada quando estes autores ressaltam a necessidade de elaborar novos modos frente aos diferentes limites impostos pela tarefa. Elaborar novos modos, ou ações, implica reinterpretar a situação presente e formular estratégias para solucionar os problemas, bem como, antecipar incidentes.

O processo descrito depende da categorização, ou seja, da forma como ocorre o reconhecimento de padrões entre os diferentes estímulos e a forma como são agrupados de maneira a elaborar modelos ou identificar características de um dado contexto ou situação. Assim, a categorização é um processo fundamental para a resolução de problemas e requer uma série de passos que, segundo STERNBERG (2000), inclui identificar e definir o problema, construir uma estratégia de resolução, organizar as informações, alocar recursos cognitivos, monitorar e avaliar a resolução.

Nessa perspectiva, a resolução de problemas depende da forma como o problema é apresentado, ou seja, se é bem ou mal estruturado com relação ao estado inicial, aos passos para resolução e ao estado final. A tomada de decisão, por sua vez, se apóia nas estratégias que o sujeito utiliza para julgar a probabilidade de acerto dentre as diferentes escolhas possíveis.

Pode-se afirmar, então, que as estratégias operatórias designam as ações que implicam um processamento controlado, ou seja, requerem um processo de atenção constante que eleva a carga cognitiva envolvida na atividade.

Um processo evolutivo e natural é a utilização de heurísticas, atalhos mentais que tornam mais leve esse processo cognitivo (STERNBERG, 2000). O preço para esta economia é o aumento na probabilidade de erros e vieses no julgamento. Segundo MARMARAS e KONTOGIANNIS (2001), as heurísticas resultam das pressões temporais e estão relacionadas ao risco envolvido na tarefa, o que eleva a probabilidade de erro no diagnóstico e na tomada de decisão.

A literatura da Psicologia Cognitiva, da Cognição Social e da Ergonomia são consensuais com relação 


\section{ADMINISTRAÇÃO DE CIÊNCIA E TECNOLOGIA - NAVEGABILIDADE E INCLUSÃO DIGITAL: USABILIDADE E COMPETÊNCIA \\ Alexandre Magno Dias Silvino - Júlia Issy Abrahão}

às principais heurísticas, seu papel adaptativo e sua possibilidade de levar o sujeito ao erro por interpretar a situação de maneira equivocada. Diferentes heurísticas podem estar envolvidas no processo de tomada de decisão, contudo as heurísticas representatividade e disponibilidade são as mais comuns devido à complexidade do raciocínio probabilístico que envolve a primeira e o processo de evocação de elementos da memória envolvido na segunda.

AMALBERTI (citado por MONTMOLLIN, 1995) sugere que, na sua relação com as competências dos trabalhadores, as estratégias heurísticas atuam como um "compromisso cognitivo" regulando atividades como as de planificação, antecipação e controle do risco. MARMARAS e KONTOGIANNIS (2001) definem competência como sendo estratégias cognitivas específicas; e heurísticas como estratégias que os operadores desenvolvem e utilizam para responder às tarefas e aos limites impostos pelo ambiente de trabalho no qual estão inseridos.

A atividade, então, é construída a partir desta gestão. Para tanto, um mecanismo de base é posto em ação consistindo em adaptar seu savoir-faire através da aprendizagem, o que provavelmente reduz a carga de trabalho para o indivíduo. Ação imprescindível nas tarefas complexas, onde o número de elementos a serem tratados requer que o sujeito adquira capacidade de avaliar e antecipar constantemente procedimentos e disfuncionamentos, devido à sua natureza dinâmica e incerta.

Em linhas gerais, a navegabilidade pode ser entendida como a articulação que o sujeito faz entre as suas competências (conhecimentos, habilidades e representações), os objetivos que ele tem ao acessar o site (serviços, informações, diversões) e as condições que cada página do site oferece para ele atingir tais objetivos. Essa articulação ocorre como uma resolução de problemas que envolve estratégias que são afetadas pela experiência que o sujeito tem em "navegar" e no assunto que é objeto da ação. Assim, quanto mais próximo à realidade do público alvo, mais o usuário dispõe de recursos para agir (representação para ação mais apropriada), elevando a probabilidade de êxito no cumprimento do objetivo.

O objetivo deste artigo, propor uma base conceitual, identificando as variáveis que favorecem a adaptação da interface gráfica e a inclusão digital, pode ser operacionalizado pelo esquema gráfico que articula as noções de competência para ação e de usabilidade. A competência do usuário é construída a partir das representações que ele tem da situação e da utilização de interfaces (softwares, internet, terminais de auto-atendimento), bem como pelas estratégias e modos operatórios adotados para obter a informação e o serviço desejado no site. A usabilidade, aferida pelos critérios ergonômicos e de funcionalidade, indica o grau de facilidade que a página oferece ao ser acessada. 


\section{Figura 2 - Esquema conceitual}

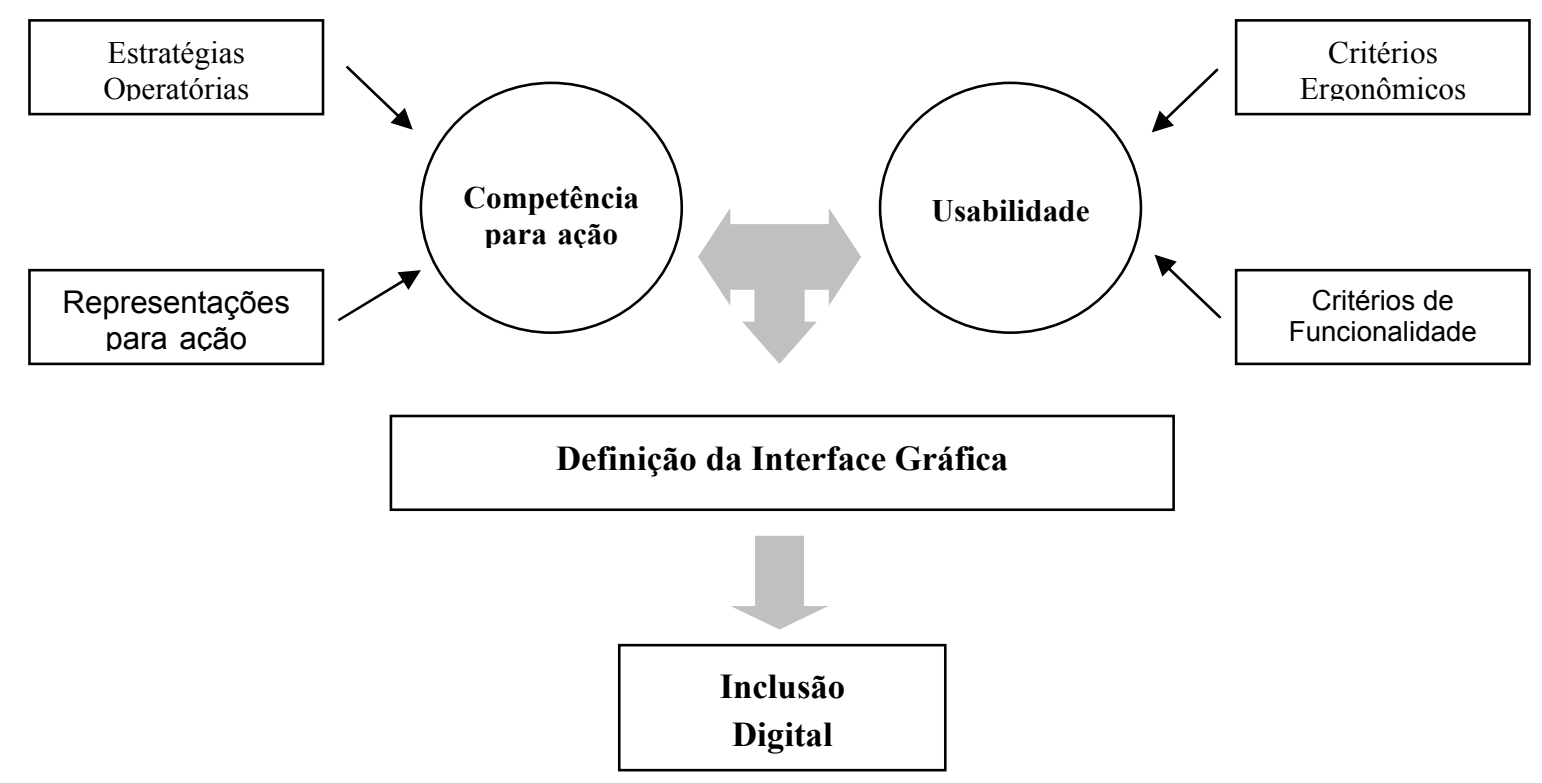

Esta centralidade no usuário, ou na sua competência, é o elemento chave que deve ser integrado às ações de inclusão digital. Ao tomar como base elementos característicos de cada público-alvo, como os descritos neste artigo, a comunicação usuário-interface é facilitada e pessoas com pouco ou nenhuma experiência em informática, baixa escolaridade e de diferentes faixas etárias podem ser privilegiadas reduzindo as fronteiras desta segregação digital.

\section{À Guisa de Conclusão}

A navegação na Internet é uma atividade complexa que exige dos sujeitos antecipações e o tratamento de um grande número de informações, podendo ser considerada como um processo constante de resolução de problemas. Portanto, a questão da inclusão digital não pode ficar restrita às dimensões de espaços públicos de acesso e de iniciação aos aplicativos mais disseminados, como usualmente vem sendo abordada.

Desta forma, a construção de um site, principalmente quando se pretende promover a inclusão digital, deve integrar as características do seu público alvo e a variabilidade inerente a ele. Não é suficiente, no entanto, elaborar o site com base no perfil demográfico (por exemplo: média de idade ou de escolaridade), deve-se também, identificar suas representações sobre os objetos em questão incorporálas ao projeto testando e avaliando as alternativas geradas, só assim, uma validação confiável é possível. Este incorporar o público alvo é um desafio quando se pensa na diversidade da população principalmente quando se acrescenta à problemática os estereótipos culturais.

Este artigo, levantou mais questões do que trouxe respostas. Ao articular conhecimentos oriundos de áreas de fronteira, aponta alguns limites e a necessidade de um trabalho de natureza interdisciplinar para a consecução dos objetivos buscados. Obviamente, a articulação proposta constituí apenas um ponto de partida, e deve ser encarada como uma primeira aproximação para a compreensão das relações entre navegabilidade e inclusão digital. Por isso mesmo, precisa ser testada com o intuito de especificar, de forma mais precisa, as relações entre as variáveis em suas diferentes dimensões visando consolidar a sua comprovação empírica. 


\section{ADMINISTRAÇÃO DE CIÊNCIA E TECNOLOGIA - NAVEGABILIDADE E INCLUSÃO DIGITAL: \\ USABILIDADE E COMPETÊNCIA \\ Alexandre Magno Dias Silvino - Júlia Issy Abrahão}

A possibilidade de modelização dos critérios mediadores da relação do usuário com a internet que incorpore as qualidades formalmente requeridas, necessita de estudos que aprofundem e fundamentem teoricamente as relações potencialmente existentes entre seus componentes e para testar as predições dele derivadas. $\mathrm{O}$ desenvolvimento de pesquisas visando validar as hipóteses levantadas ao longo deste trabalho, favorecerá a obtenção de dados que servirão de insumos à diferentes organizações que investem na prestação de serviços via internet.

Não obstante as dificuldades apontadas, buscar soluções que viabilizem o acesso às informações e aos serviços oferecidos por internet constitui um salto qualitativo na relação Estado-cidadão, elevando a qualidade e rapidez dos serviços e avançando mais um passo na direção de um estado igualitário e justo. Neste sentido, as ações que favorecem a inclusão digital seguramente trarão consigo não somente os clientes de baixa escolaridade e baixa renda, mas também clientes com outras características especiais. Por exemplo os indivíduos pertencentes à terceira idade, que se apresentam hoje como uma faixa da população promissora em termos de consumo desses serviços.

\section{Artigo recebido em 28.01.2003. Aprovado em 27.05.2003}

\section{Referências}

ABRAHÃO, J. e PINHO, D. L. M. Teoria e Prática Ergonômica: Seus limites e possibilidades. Em: M. G. T. PAZ e A. TAMAYO (Ed.). Escola, Saúde e Trabalho: estudos psicológicos. Brasília: Editora Universidade de Brasília, 1999.

ADELSON, B. When Novices Surpass Experts: The Difficulty of a Task May Increase With Expertise. Journal of Experimental Psychology, 10(3): 483-495, 1984.

AMALBERTI, J. Savoir-faire de l'opérateur: Aspects théoriques et pratiques en ergonomie. Em: J. Amalberti, M. de Montmollin e J. Thereau. (Ed.). Modeles en Analyse du Travail. Liège: Mardage, (1991).

ANDERSON, J. R. Cognitive Psychology and Its Implications. New York: Worth Publishers, 2000. p. 105-351.

BASTIEN, C. Validation de critères ergonomiques pour l'évaluation d'interfaces utilisateurs. Rapports de Recherche (1427). Rocquencourt: INRIA, 1991.

BASTIEN, C. Critères ergonomiques de Scapin et Bastien. Disponível em:

$<$ www.ergoweb.ca/criteres.html > Acesso em: 27/01/2003.

BEST, J. B. Cognitive Psychology. New York: West Publishing Company, (1995).

CANÃS, J. J. e WAERNS, Y. Ergonomía Cognitiva. Aspectos psicológicos de la interacción de las personas con la tecnologia de la información. Madrid: Editorial Medica Panamericana, 2001.

CYBIS, W. A. Critérios Ergonômicos para Avaliação de Interfaces Homem - Computador (Última atualização 05/11/2002). Disponível em: <http://www.labiutil.inf.ufsc.br> Acesso em: 10 janeiro 2003.

COMITÊ PARA A DEMOCRATIZAÇÃO DA INFORMÁTICA. As Eleições 2002 e a Inclusão 


\section{ADMINISTRAÇ̃̃O DE CIÊNCIA E TECNOLOGIA - NAVEGABILIDADE E INCLUSÃO DIGITAL: \\ USABILIDADE E COMPETÊNCIA \\ Alexandre Magno Dias Silvino - Júlia Issy Abrahão}

Digital. Disponível em: <www.cdi.org.br/midia/artigos> Acesso em: 27/01/2003.

GREEN, T. R. G. e HOC, J. -M. What is Cognitive Ergonomics?. Le Travail Humain, 54(4): 291-304, 1991.

GUÉRIN, F., LAVIlle, A., DANiEllou, F., DURAFFOURG, J. e KERGUELEN, A. Compreender o trabalho para transformá-lo. A prática da Ergonomia. Tradução de: L. Sznelwar et al. São Paulo: Edgard Blücher LTDA, 2001.

HANISCH, K. A., KRAMER, A. F. e HULIN, C. L. Cognitive representations, control, and understanding of complex systems: a field study focusing on components of user's mental models and expert/novice differences. Ergonomics, 34(8): 1129-1145, 1991.

HOC, J. -M e LIÉNARD, J. -S. A cognição em situação de trabalho. Le Courrier du CNRS. Dossiers Scientifiques, 79: 98-99, 1990.

HOLLNAGEL, E. Cognitive Ergonomics: It's all in the Mind. Ergonomics, 40(10): 1170-1182, 1997.

KOUBEK, J. R. \& SALVENDY, G. Cognitive performance of super-experts on computer program modification tasks. Ergonomics, 34(8): 1095-1112, 1991.

LEPLAT, J. L’analyse du Travail. Revue de Psychologie Appliquée, 31(1): 9-27, 1986.

MARMARAS, N. e PAVARD, B. Problem-Driven Approach to the Design of Information Technology Systems Supporting Complex Cognitive Tasks. Cognition, Technology \& Work. London: Springer-Verlag London Limited, 2000.

MARMARAS, N. e KONTOGIANNIS. Cognitive Tasks. Em: G. Salvendy. Handbook of Industrial Engineering. New York: John Wiley \& Sons, 2001.

MONTMOLLIN, M. Vocabulaire de l'Ergonomie. Toulouse: Octarès Editions, 1995.

OCHANINE, D. A. The operative image of controlled capacities of man. Em: LEPLAT, J. (Ed.). L'analyse du travail en psychologie ergonomique. Toulouse: Octares Éditions, 1992.

PROGRAMA DAS NAÇÕES UNIDAS PARA O DESENVOLVIMENTO - PNUD. Relatório do Desenvolvimento Humano - 2002. Disponível em:

< http://www.undp.org/hdr2002/chapterthree.pdf > Acesso em: 27/01/2003.

REVISTA DA SOCIEDADE DIGITAL. Cidadania pela Internet garante a Democracia. Brasília: Chantal Editora LTDA, v. 1, n. 4, setembro 2002, 46 p.

SARMET, M. M. e SILVINO, A. M. D. Elaboração de um instrumento para avaliação de páginas de internet: a perspectiva do usuário. Em: Abergo 2002 - VII Congresso Latino-Americano, XII Congresso Brasileiro de Ergonomia. Anais do ABERGO 2002. Recife: ABERGO, 2002. Poster 040. 1 CD-ROM.

SCAPIN, D. L. Organizing human factors knowledge for the evaluation and design 0interfaces. 
International Journal of Human-Computer Interation, 2(3): 203-229, 1990.

STERNBERG, R. J. Psicologia Cognitiva. Porto Alegre: ArtMed Editora, 2000.

TEIGER, C. Représentation du travail, travail de la représentation. Em: A. WEILL-FASSINA, P. RABARDEL e D. DUBOIS (Ed.). Représentation pour l'action. Toulouse: Octarès Editions, 1993. p. 311-344.

TEIXEIRA, J. Naturalismo e Representação Mental. Em: Abrantes, P. (Ed.). Epistemologia e Cognição. Brasília: Editora Universidade de Brasília, 1993.

WEILL-FASSINA, A. L'analyse des aspects cognitifs du travail. Em: DADOY, M. e cols. Les Analyses du Travail. Enjeux et Formes. Paris: CEREQ, 1990. 